Research Article

\title{
A Cross-Sectional Study on Knowledge of Breastfeeding and Knowledge and Practice of Personal Hygiene and Sanitation among Antenatal Mothers in a Tertiary Hospital of Kolkata, West Bengal
}

\author{
Maithili Ghosh', Kunal Kanti Majumdar ${ }^{2}$ \\ ${ }^{1}$ Research Scholar, KPC Medical College and Hospital, Jadavpur, Kolkata, India. \\ ${ }^{2}$ Professor, Department of Community Medicine, KPC Medical College and Hospital, Jadavpur, Kolkata, India. \\ DOI: https://doi.org/10.24321/2454.325X.202001
}

\section{I $\quad \mathbf{N} \quad \mathbf{F} \quad \mathbf{O}$}

\section{Corresponding Author:}

Kunal Kanti Majumdar, Department of Community Medicine, KPC Medical College and Hospital, Jadavpur, Kolkata, India.

E-mail Id:

kunalmajumdar1@gmail.com

Orcid Id:

https://orcid.org/0000-0002-7128-5483

How to cite this article:

Ghosh M, Majumdar KK. A Cross-Sectional Study on Knowledge of Breastfeeding and Knowledge and Practice of Personal Hygiene among Antenatal Mothers in a Tertiary Hospital of Kolkata, West Bengal. Int J Preven Curat Comm Med 2020; 6(1): 3-14.

Date of Submission: 2020-09-04

Date of Acceptance: 2020-09-17

\section{$\begin{array}{llllllll}\mathbf{A} & \mathbf{B} & \mathbf{S} & \mathbf{T} & \mathbf{R} & \mathbf{A} & \mathbf{C} & \mathbf{T}\end{array}$}

Background: Breastfeeding is beneficial for both the mother and child. Exclusive breastfeeding protects the child from various infections. It reduces the risks of ovarian and breast cancer in the mother. Poor hygienic and sanitary practices during pregnancy may lead to various infective conditions and adverse obstetric outcomes leading to increased maternal and neonatal morbidity and mortality.

Objectives: To determine the breastfeeding knowledge and knowledge and practice of personal hygiene and sanitation among the antenatal mothers.

Methodology: A cross-sectional study was performed in a tertiary hospital in Kolkata. 170 antenatal mothers were selected for the study. Data was collected on breastfeeding knowledge and knowledge and practice of personal hygiene and sanitation.

Result: $41.8 \%$ of antenatal mothers were between $25-30$ years of age. According to $98.2 \%$ opined that breastmilk should be fed to the child first after birth. 75.9\% of them cleaned their teeth twice daily, $72.4 \%$ bathed once in a day. $83.5 \%$ of them regularly washed their nipples with soap and water. $99.4 \%$ washed their hands before eating and after using the toilet, $75.9 \%$ had no idea about the 6 steps of hand washing. $37.7 \%$ used domestic filter as their source of drinking water. $7.1 \%$ used community toilets and $44.7 \%$ knows the usefulness of sanitary toilet.

Conclusion: In this study, it was found that most of the mothers had adequate knowledge about the importance of colostrum and exclusive breastfeeding and the correct time of initiating complementary feeding. Knowledge as well as practices of hygiene and sanitation were also found to be satisfactory.

Keywords: Antenatal, Breastfeeding, Hygiene, Knowledge, Practice, Sanitation 


\section{Introduction}

On the basis of nutritional and economic grounds, breast milk is the ideal food for infants in the first months of life. It provides the necessary nutrients and energy to an infant in the first months of life and it continues to provide them upto half or more of a child's nutritional needs during the second half of the first year and upto one-third during the second year of life. ${ }^{1}$

Under normal conditions, Indian mothers secrete 450$600 \mathrm{ml}$ of milk daily with $1.1 \mathrm{gm}$ protein per $100 \mathrm{~mL}$; the energy value of human milk is $70 \mathrm{kcal} / 100 \mathrm{~mL} .^{2}$ Inadequate milk intake leads to lethargy, delayed passing of stool, decreased urine output, weight loss greater than $7 \%$ of body weight, hypernatremic dehydration and increased hunger in infants. ${ }^{3}$

Breast milk is often referred to as the "first vaccination for babies against diseases" ${ }^{4}$ by virtue of the anti-infective factors present in it which provide natural passive immunity to the child. It provides protection against acute disorders like diarrhoea, urinary tract infections, otitis media, necrotising enterocolitis, infant botulism, septicaemia, chronic disorders like Type 1 Diabetes Mellitus, Coeliac disease, Crohn's disease, childhood cancer (lymphoma, leukaemia), recurrent otitis media, allergy; obesity, thereby decreasing hospitalisations and infant mortality. ${ }^{3}$ It promotes improved cognitive development (maybe due to the presence of $\omega-3$ fatty acids, particularly docosahexaenoic acid). ${ }^{5}$

The American Academy of Paediatrics recommends exclusive breastfeeding for at least the first 4 months of life and preferably the first 6 months of life to tackle infant nutrition and survival. ${ }^{3}$

The health and nutritional status of mothers and children are interlinked. Breastfeeding contributes much to the maternal health and well-being, reducing the risks of ovarian and breast cancer. ${ }^{6}$ It also reduces the chances of post-partum psychosis and post-partum haemorrhage by accelerating the process of uterine involution. ${ }^{6}$

Antenatal period is a vital period in a woman's life. Maintenance of personal hygiene during this period is of utmost importance as pregnancy is often associated with increased susceptibility to infections. This maybe due to the physiological, anatomical and biochemical changes that occur in the body of antenatal mothers particularly the increase in hormonal levels, suppression of the immune system and may also account for the increase in the excretion of sweat, mucous, urine, saliva etc. ${ }^{7}$

Unhygienic practices prevalent among the antenatal mothers include use of insanitary latrines, improper washing of hands without soap, use of dirty and wet underwear etc. which increase the susceptibility to infections.
Hormonal changes during pregnancy along with neglected oral hygiene often lead to gingivitis and periodontitis in the antenatal mothers. ${ }^{8}$ The physiological increase in plasma volume results in urine concentration and about $70 \%$ of pregnant women develop glycosurea which facilitates bacterial growth in urine. Thus genital hygiene during pregnancy is to be stressed as pregnancy enhances the progression from asymptomatic to symptomatic bacteriuria which may lead to pyelonephritis and obstetric outcomes like prematurity, low birth weight and increased neonatal mortality. ${ }^{9}$

\section{Aims and Objectives}

- $\quad$ To determine the breastfeeding knowledge among the antenatal mothers in a tertiary hospital of Kolkata.

- To determine the knowledge and existing practice of personal hygiene and sanitation among the antenatal mothers in a tertiary hospital of Kolkata.

\section{Material and Methods}

Study Design: It is an observational, descriptive and crosssectional study.

Study Setting: The study was conducted in the Department of Gynaecology and Obstetrics of a tertiary hospital in Kolkata.

Study Period: The study was completed in a period of two months, i.e, between 1.07.19 and 1.09.19.

Study Population: All the antenatal mothers attending the OPD and those admitted in the Obstetrics ward of the Gynaecology and Obstetrics Department of a tertiary hospital in Kolkata during the study period.

\section{Study Technique}

- The questionnaire was pre-tested among 30 antenatal mothers prior to the initiation of the study and necessary modifications were made accordingly. The participants of the pretest were not included in the study.

\section{Sampling Technique}

- Consecutive sampling was done for the antenatal mothers attending the OPD of the Gynaecology and Obstetrics Department of a tertiary hospital in Kolkata during the study period.

- Complete enumeration was done for the antenatal mothers admitted in the Obstetrics ward of the Gynaecology and Obstetrics Department of a tertiary hospital in Kolkata during the study period.

- Sample Size: A total of 120 antenatal mothers who visited the OPD of the Gynaecology and Obstetrics Department of a tertiary hospital in Kolkata during the study period was selected for the study by consecutive 
sampling. Another 50 antenatal mothers admitted in the Obstetrics ward of the Gynaecology and Obstetrics Department of a tertiary hospital in Kolkata during the study period were selected for the study by complete enumeration. Therefore, the total sample size is 170 $(120+50)$.

- $\quad$ Selection Criteria: The study subjects were selected as per the following criteria:

\section{Inclusion Criteria}

Antenatal mothers attending the OPD and those admitted in the Obstetrics ward of a tertiary hospital in Kolkata who were willing to participate in the study and gave written consent were included in the study.

\section{Exclusion Criteria}

- Antenatal mothers who were critically ill and not in a state to participate in the study.

- Antenatal mothers not willing to participate in the study and not giving written consents.

\section{Method of Data Collection}

- The antenatal mothers fulfilling the inclusion criteria were chosen for participation in the study.

- $\quad$ After taking informed consent, they were interviewed and given a pre-designed pre-tested questionnaire for data capture.

- The hygiene practices of the antenatal mothers admitted in the Obstetrics ward of the Gynae-cology and Obstetrics Department of a tertiary hospital in Kolkata were also observed during the study period.

- They were assured that their personal details would be kept private and used solely for the pur-pose of this study.

\section{Study Tools}

- A pre-designed pre-tested questionnaire for data collection. The questionnaire consists of the following parts:

Part 1: It includes the personal details of the participating antenatal mothers (name, age, address, number of pregnancies etc.) and their socio-demographic details (literacy, occupation, family income).

Part 2: It includes questions related to the knowledge regarding the importance and necessity of breastfeeding.

Part 3: It includes questions related to the knowledge and practice of personal hygiene and sanitation.

- Informed consent form was also filled before data collection.

Data Analysis: The collected data was analysed by descriptive and analytical statistical methods.

Ethical Clearance: Ethics approval was obtained from the
Institutional Ethics Committee prior to the conduction of the study.

Informed consents were also obtained from the participating antenatal mothers.

\section{Result}

\section{Sociodemographic Profile}

It was found from the study that majority of the interviewed antenatal mothers were housewives (98.2\%) and $41.8 \%$ were in the age group 25-30 years. Equal proportion of the antenatal mothers resided in urban and rural areas. $46.5 \%$ of the antenatal mothers had completed only their secondary education. $2.9 \%$ of them were illiterate. Among the husbands, majority (48.8\%) had completed only their secondary education. According to modified BG Prasad socioeconomic classification (2019), ${ }^{10}$ majority of the study population (43.5\%) belonged to upper middle class. $63.5 \%$ of the antenatal mothers were primigravida while the rest were multigravida. Majority of them (58.8\%) had had more than 4 antenatal checkups at the time of the interview (Table 1).

Table I.Distribution of the Interviewed Antenatal Mothers according to their Sociodemographic Profile $(\mathbf{N}=170)$

\begin{tabular}{|c|c|c|}
\hline & Number & Pecentage \\
\hline \multicolumn{3}{|c|}{ Age Group of Antenatal Mother } \\
\hline Between 17-20 years & 16 & $9.4 \%$ \\
\hline Between 20-25 years & 66 & $38.8 \%$ \\
\hline Between 25-30 years & 71 & $41.8 \%$ \\
\hline Above 30 years & 17 & $10 \%$ \\
\hline Occupation of Antenatal Mother \\
\hline Housewife & 167 & $98.2 \%$ \\
\hline Employed & 3 & $1.8 \%$ \\
\hline \multicolumn{3}{|c|}{ Residence of Antenatal Mother } \\
\hline Urban & 85 & $50 \%$ \\
\hline Rural & 85 & $50 \%$ \\
\hline
\end{tabular}

Educational Qualification of Antenatal Mother

\begin{tabular}{|c|c|c|}
\hline Illiterate & 5 & $2.9 \%$ \\
\hline Primary & 15 & $8.8 \%$ \\
\hline Secondary & 79 & $46.5 \%$ \\
\hline Higher Secondary & 23 & $13.5 \%$ \\
\hline Graduate & 34 & $20 \%$ \\
\hline Post-graduate & 14 & $8.3 \%$ \\
\hline \multicolumn{3}{|c|}{ Educational Qualification of Husband } \\
\hline Illiterate & 3 & $1.8 \%$ \\
\hline Primary & 18 & $10.6 \%$ \\
\hline
\end{tabular}




\begin{tabular}{|c|c|c|}
\hline Secondary & 83 & $48.8 \%$ \\
\hline Higher Secondary & 18 & $10.6 \%$ \\
\hline Graduate & 43 & $25.3 \%$ \\
\hline Post-graduate & 5 & $2.9 \%$ \\
\hline
\end{tabular}

Socio-Economic Status (According To Modified BG Prasad Classification $2019^{10}$ )

\begin{tabular}{|c|c|c|}
\hline Upper Class & 66 & $38.8 \%$ \\
\hline Upper Middle Class & 74 & $43.5 \%$ \\
\hline Middle Class & 10 & $5.9 \%$ \\
\hline Lower Middle Class & 11 & $6.5 \%$ \\
\hline Lower Class & 9 & $5.3 \%$ \\
\hline Gravida \\
\hline Primigravida & 108 & $63.5 \%$ \\
\hline Multigravida & 62 & $36.5 \%$ \\
\hline
\end{tabular}

Number of Antenatal Checkups During Pregnancy

\begin{tabular}{|c|c|c|}
\hline 1 & 12 & $7.1 \%$ \\
\hline 2 & 17 & $10 \%$ \\
\hline 3 & 18 & $10.6 \%$ \\
\hline 4 & 23 & $13.5 \%$ \\
\hline$>4$ & 100 & $58.8 \%$ \\
\hline
\end{tabular}

\section{Breastfeeding Knowledge}

It was observed in the study that $45.9 \%$ of the interviewed antenatal mothers were explained about the importance of exclusive breastfeeding during the first 6 months by health staffs during these visits.

Majority of them (73.5\%) believed that colostrum should be fed to the child. Among them, $66.4 \%$ cited growth and development of child as well as development of immunity in the child as the reasons for feeding colostrum while $0.8 \%$ of them was of the opinion that colostrum is rich in cholesterol and should be fed to the child and the remaining $32.8 \%$ did not know why it should be fed. $8.8 \%$ of the antenatal mothers opined that colostrum should be discarded while $17.7 \%$ did not know what colostrum is (Table 2 ).

Table 2.Distribution of the interviewed antenatal mothers according to their breastfeeding knowledge $(\mathbf{N}=170)$

\begin{tabular}{|c|c|c|}
\hline & Number & Pecentage \\
\hline \multicolumn{3}{|c|}{$\begin{array}{l}\text { Instance of Any Health Staff Explaining about the } \\
\text { Importance of Exclusive Breastfeeding for the First } 6 \\
\text { Months }\end{array}$} \\
\hline Yes & 78 & $45.9 \%$ \\
\hline No & 92 & $54.1 \%$ \\
\hline \multicolumn{3}{|c|}{ What Should be Done with the Colostrum } \\
\hline
\end{tabular}

\begin{tabular}{|c|c|c|}
\hline To be fed to the child & 125 & $73.5 \%$ \\
\hline To be discarded & 15 & $8.8 \%$ \\
\hline Do not know what colostrum is & 30 & $17.7 \%$ \\
\hline \multicolumn{3}{|c|}{ Importance of Feeding the Colostrum ( $n=125)$} \\
\hline $\begin{array}{l}\text { It protects the child from future } \\
\text { diseases and is rich in nutrients } \\
\text { that help in the growth of the } \\
\text { child }\end{array}$ & 83 & $66.4 \%$ \\
\hline Other reasons & 1 & $0.8 \%$ \\
\hline Do not know & 41 & $32.8 \%$ \\
\hline \multicolumn{3}{|c|}{ What Should be First Fed to the Child after Birth } \\
\hline Breastmilk & 167 & $98.2 \%$ \\
\hline Honey & 3 & $1.8 \%$ \\
\hline Water or sugar water & - & - \\
\hline Breastmilk Supplements & - & - \\
\hline \multicolumn{3}{|c|}{$\begin{array}{c}\text { What will Provide the Best Nutrition to the Child } \\
\text { During the First } 6 \text { Months }\end{array}$} \\
\hline Exclusive breastfeeding & 161 & $94.7 \%$ \\
\hline Breastmilk supplements & 2 & $1.2 \%$ \\
\hline $\begin{array}{l}\text { Combined breastfeeding and } \\
\text { breastmilk supplements }\end{array}$ & 7 & $4.1 \%$ \\
\hline
\end{tabular}

If Breastmilk Supplements alone or with Breastmilk is considered to be the Best for the Child, the Reason behind such thought $(n=9)$

\begin{tabular}{|c|c|c|}
\hline Relatives or friends have told so & 3 & $33.3 \%$ \\
\hline $\begin{array}{c}\text { Advertisements have convinced } \\
\text { the importance of breastmilk } \\
\text { supplements }\end{array}$ & 6 & $66.7 \%$ \\
\hline \begin{tabular}{c} 
ing \\
\hline
\end{tabular} & & \\
\hline
\end{tabular}

The Time for which the Child Should be Exclusively Breastfed

\begin{tabular}{|c|c|c|}
\hline The first 2 months & 6 & $3.5 \%$ \\
\hline The first 4 months & 5 & $2.9 \%$ \\
\hline The first 6 months & 137 & $80.6 \%$ \\
\hline Till 1 year & 6 & $3.5 \%$ \\
\hline$>1$ year & 16 & $9.5 \%$ \\
\hline
\end{tabular}

Water can be Fed to the Child along with Breastmilk During Exclusive Breastfeeding

\begin{tabular}{|c|c|c|}
\hline Yes & 93 & $54.7 \%$ \\
\hline No & 63 & $37.1 \%$ \\
\hline Do not know & 14 & $8.2 \%$ \\
\hline \multicolumn{3}{|c|}{ How often the Child Should be Breastfed } \\
\hline Every $10-15$ mins & 1 & $0.6 \%$ \\
\hline Every $1-2$ hours & 74 & $43.5 \%$ \\
\hline Every 2-3 hours & 23 & $13.5 \%$ \\
\hline
\end{tabular}




\begin{tabular}{|c|c|c|}
\hline $\begin{array}{l}\text { Every time the child seems } \\
\text { hungry }\end{array}$ & 64 & $37.7 \%$ \\
\hline Do not know & 8 & $4.7 \%$ \\
\hline \multicolumn{3}{|c|}{$\begin{array}{l}\text { Time when First Food to be Given with Breastmilk as } \\
\text { Supplementary Feed }\end{array}$} \\
\hline Within 6 months after birth & 14 & $8.2 \%$ \\
\hline After 6 months post birth & 156 & $91.8 \%$ \\
\hline \multicolumn{3}{|c|}{$\begin{array}{l}\text { Breastfeeding should be Completely stopped when } \\
\text { the Child is }\end{array}$} \\
\hline Under 6 months of age & 1 & $0.6 \%$ \\
\hline At 6 months of age & 8 & $4.7 \%$ \\
\hline $\begin{array}{l}\text { Between } 6-12 \text { months } \\
\text { of age }\end{array}$ & 5 & $2.9 \%$ \\
\hline$>12$ months of age & 81 & $47.7 \%$ \\
\hline$>24$ months of age & 75 & $44.1 \%$ \\
\hline \multicolumn{3}{|c|}{$\begin{array}{l}\text { In Case of Employed Women, Once the Mother } \\
\text { Rejoins Work within } 6 \text { Months after the Birth of the } \\
\text { Child, the Child will then be Fed }(n=3)\end{array}$} \\
\hline Only breastmilk & - & - \\
\hline Breastmilk supplements & - & - \\
\hline $\begin{array}{l}\text { Combined breastmilk and } \\
\text { breastmilk supplements }\end{array}$ & 3 & $100 \%$ \\
\hline \multicolumn{3}{|c|}{$\begin{array}{c}\text { Practice of Taking any Drugs During Pregnancy } \\
\text { without the Knowledge of the Doctor }\end{array}$} \\
\hline Yes & - & - \\
\hline No & 170 & $100 \%$ \\
\hline \multicolumn{3}{|c|}{$\begin{array}{l}\text { Know if Certain Drugs Can affect the Child through } \\
\text { Breastmilk if they are Taken by the Mother buring the } \\
\text { Lactation Period }\end{array}$} \\
\hline Yes & 33 & $19.4 \%$ \\
\hline No & 137 & $80.6 \%$ \\
\hline \multicolumn{3}{|c|}{$\begin{array}{l}\text { If yes, the Drugs that can affect the Child through } \\
\text { Breastmilk include }(n=33)\end{array}$} \\
\hline Analgesics & 4 & $12.1 \%$ \\
\hline Anti-allergic drugs & 5 & $15.2 \%$ \\
\hline Cannot name any & 24 & $72.7 \%$ \\
\hline \multicolumn{3}{|c|}{$\begin{array}{l}\text { Opinion about the Statement "Breastmilk } \\
\text { Supplements and Breastmilk have the Same } \\
\text { Nutritional Value." }\end{array}$} \\
\hline True & 39 & $22.9 \%$ \\
\hline False & 131 & $77.1 \%$ \\
\hline \multicolumn{3}{|c|}{$\begin{array}{l}\text { Opinion about the Statement "Breastmilk } \\
\text { Supplements are Digested Better than Breastmilk." }\end{array}$} \\
\hline True & 34 & $20 \%$ \\
\hline False & 136 & $80 \%$ \\
\hline
\end{tabular}

Among those who believed that colostrum should be fed to the child included $62.9 \%$ of the primigravida women and $91.9 \%$ of the multigravida women. $9.25 \%$ of the primigravida women and $8 \%$ of the multigravida women opined that it should be discarded while 17.7 of the study participants who did not know what colostrum is were all primigravida (Figure 1). Therefore, the knowledge about colostrum was better among multigravida women.

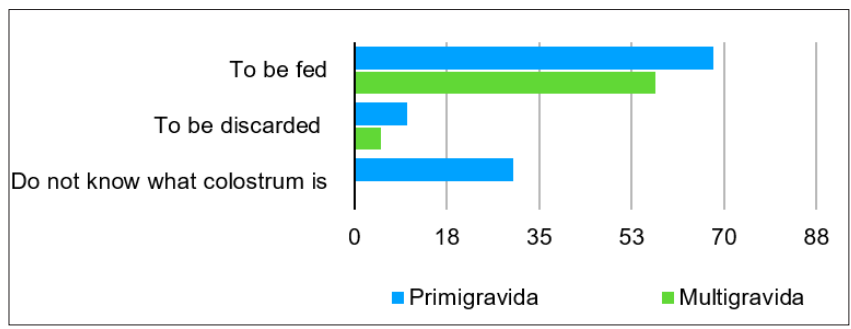

Figure I.Knowledge about colostrum

Table 3.Distribution of the Interviewed Antenatal Mothers according to their Knowledge and Practice of Oral Hygiene $(\mathbf{N}=\mathbf{I 7 0})$

\begin{tabular}{|c|c|c|}
\hline & Number & Percentage \\
\hline \multicolumn{3}{|c|}{ Number of Times of Brushing/ Cleaning Teeth } \\
\hline Once a day & 34 & $20 \%$ \\
\hline Twice a day & 129 & $75.9 \%$ \\
\hline More than twice a day & 7 & $4.1 \%$ \\
\hline \multicolumn{3}{|c|}{ Importance of Daily Cleaning the Teeth } \\
\hline $\begin{array}{l}\text { So that food is not stuck } \\
\text { anywhere in the mouth and } \\
\text { the mouth is kept clean }\end{array}$ & 71 & $41.8 \%$ \\
\hline Topreventgumdiseases & 26 & $15.3 \%$ \\
\hline To prevent bad breath & 68 & $40 \%$ \\
\hline Do not know & 5 & $2.9 \%$ \\
\hline \multicolumn{3}{|c|}{ Time when the Teeth are Cleaned } \\
\hline Before breakfast & 33 & $19.4 \%$ \\
\hline Before going to bed at night & 1 & $0.6 \%$ \\
\hline $\begin{array}{l}\text { Both before breakfast and } \\
\text { before going to bed at night }\end{array}$ & 129 & $75.9 \%$ \\
\hline Every time after major meals & 4 & $2.4 \%$ \\
\hline Others & 3 & $1.7 \%$ \\
\hline \multicolumn{3}{|c|}{$\begin{array}{l}\text { Importance of cleaning the teeth before going to bed } \\
\qquad \text { at night }(n=136)\end{array}$} \\
\hline To prevent dental caries & 132 & $77.6 \%$ \\
\hline Just to prevent bad breath & 9 & $5.3 \%$ \\
\hline $\begin{array}{l}\text { Just to keep the mouth } \\
\text { clean }\end{array}$ & 19 & $11.2 \%$ \\
\hline Do not know & 10 & $5.9 \%$ \\
\hline
\end{tabular}




\begin{tabular}{|c|c|c|}
\hline \multicolumn{3}{|c|}{ The Teeth are Cleaned with } \\
\hline Toothbrush & 166 & $97.6 \%$ \\
\hline Fingers & 2 & $1.2 \%$ \\
\hline Twigs & 2 & $1.2 \%$ \\
\hline
\end{tabular}

If Toothbrush is Used, Number of Times it is Changed ( $n=166)$

\begin{tabular}{|c|c|c|}
\hline Once in a month & 40 & $24.1 \%$ \\
\hline Once in 2 months & 58 & $34.9 \%$ \\
\hline Once in 3 months & 33 & $19.9 \%$ \\
\hline Once in 6 months & 25 & $15.1 \%$ \\
\hline $\begin{array}{c}\text { Every time when the brush is } \\
\text { damaged }\end{array}$ & 10 & $6 \%$ \\
\hline
\end{tabular}

\begin{tabular}{|c|c|c|}
\hline \multicolumn{3}{|c|}{ Substance Used to Clean the Teeth } \\
\hline Toothpaste & 166 & $97.6 \%$ \\
\hline Tooth powder & 2 & $1.2 \%$ \\
\hline Guraku & 1 & $0.6 \%$ \\
\hline Ash & 1 & $0.6 \%$ \\
\hline
\end{tabular}

Most of the antenatal mothers (98.2\%) opined that breastmilk should be fed to the child first after birth while the others were of the opinion that honey should be fed first. $94.7 \%$ of the study population answered that exclusive breastfeeding is the best source of nutrients for their children in the first 6 months of life while the remaining considered breastmilk substitutes alone or with breastmilk as the best source. Majority $(80.6 \%)$ of the antenatal mothers opined that the child should be exclusively breastfed in the first 6 months and $54.7 \%$ believed that water should be given to the child during exclusive breastfeeding. Majority (43.5\%) of them answered that their children should be breastfed every 1-2 hours. Most of them (91.8\%) knew about the correct age of starting complementary feeding. $47.7 \%$ of the antenatal mothers opined that breastfeeding should be stopped after 1 year post the birth of their child while $44.1 \%$ were of the opinion that it should be stopped after 2 years.

All the working antenatal mothers preferred to feed their children combined breastmilk and breastmilk supplements once they rejoined work within 6 months after their delivery.

Majority of the interviewed antenatal mothers (80.6\%) did not know that certain drugs can reach their children through breastmilk and affect them accordingly.

$77.1 \%$ of the antenatal mothers did not believe that breastmilk supplements and breastmilk have the same nutritional value while $80 \%$ believed that breastmilk is digested faster than breastmilk supplements (Table 2).

\section{Knowledge and Practice of Oral Hygiene}

The study revealed that majority of the interviewed antenatal mothers $(75.9 \%)$ cleaned their teeth twice daily, i.e, before breakfast and before going to bed at night among which $53.5 \%$ of the antenatal mothers belonged to urban population while $46.5 \%$ of them belonged to rural population. $19.4 \%, 0.6 \%$ and $2.4 \%$ cleaned their teeth only after breakfast, before going to bed at night, after every major meal, respectively while $1.7 \%$ cleaned their teeth after every major meal and after bathing.

Most of the antenatal mothers (77.6\%) believed that it is important to clean their teeth before going to bed at night to prevent dental caries. Majority (97.6\%) used toothbrush and toothpaste to clean their teeth. 34.9\% changed their toothbrush once in 2 months and $15.1 \%$ once in 6 months (Table 3).

Table 4.Distribution of the Interviewed Antenatal Mothers according to their Knowledge And Practice Of Bathing And Genital Hygiene ( $N=170)$

\begin{tabular}{|c|c|c|}
\hline & Number & Percentage \\
\hline \multicolumn{3}{|c|}{ Number of Times the Mothers Take Bath } \\
\hline Once a day & 123 & $72.4 \%$ \\
\hline Twice a day & 42 & $24.7 \%$ \\
\hline More than twice a day & 5 & $2.9 \%$ \\
\hline \multicolumn{3}{|c|}{ Importance of Daily Bathing } \\
\hline $\begin{array}{l}\text { Just to keep the body clean } \\
\text { and to keep away bad odour }\end{array}$ & 63 & $37.1 \%$ \\
\hline To feel refreshed & 17 & $10 \%$ \\
\hline $\begin{array}{c}\text { To keep away germs and } \\
\text { diseases }\end{array}$ & 90 & $52.9 \%$ \\
\hline \multicolumn{3}{|c|}{ Number of Times Shampoo is Used to Clean Hair } \\
\hline Once a week & 48 & $28.2 \%$ \\
\hline 2-3 times a week & 122 & $71.8 \%$ \\
\hline \multicolumn{3}{|c|}{ How Often Soap is used while Bathing } \\
\hline Every time while bathing & 150 & $88.2 \%$ \\
\hline Occasionally & 20 & $11.8 \%$ \\
\hline Never & - & - \\
\hline \multicolumn{3}{|c|}{ Clothes Changed after Bathing } \\
\hline Yes & 162 & $95.3 \%$ \\
\hline No & 8 & $4.7 \%$ \\
\hline \multicolumn{3}{|c|}{ Number of Times the Genital Area is Cleaned } \\
\hline $\begin{array}{c}\text { Every time after going to the } \\
\text { toilet }\end{array}$ & 60 & $35.3 \%$ \\
\hline Twice a day & 17 & $10 \%$ \\
\hline Once a day & 76 & $44.7 \%$ \\
\hline
\end{tabular}




\begin{tabular}{|c|c|c|}
\hline Once in 2 days & 7 & $4.1 \%$ \\
\hline Once a week & 6 & $3.5 \%$ \\
\hline Never & 4 & $2.4 \%$ \\
\hline \multicolumn{3}{|c|}{ Soap Used to Wash the Genital Area } \\
\hline Yes & 130 & $76.5 \%$ \\
\hline No & 40 & $23 \%$ \\
\hline \multicolumn{3}{|c|}{$\begin{array}{c}\text { Nipples Cleaned Regularly with Soap and Water } \\
\text { While Bathing }\end{array}$} \\
\hline Yes & 142 & $83.5 \%$ \\
\hline No & 28 & $16.5 \%$ \\
\hline \multicolumn{3}{|c|}{$\begin{array}{l}\text { Importance of Cleaning Nipples Regularly with Soap } \\
\text { and Water }(n=142)\end{array}$} \\
\hline Just to keep the nipples clean & 37 & $26.1 \%$ \\
\hline $\begin{array}{l}\text { To keep the nipples free from } \\
\text { germs so as to protect the } \\
\text { newborn from infections } \\
\text { during the lactation period }\end{array}$ & 100 & $70.4 \%$ \\
\hline Do not know & 5 & $3.5 \%$ \\
\hline \multicolumn{3}{|c|}{$\begin{array}{l}\text { How Often the Undergarments are Changed during } \\
\text { Pregnancy }\end{array}$} \\
\hline Once a day & 44 & $25.9 \%$ \\
\hline Twice a day & 38 & $22.3 \%$ \\
\hline Once in 2 days & 2 & $1.2 \%$ \\
\hline Once a week & 1 & $0.6 \%$ \\
\hline Do not use undergarments & 85 & $50 \%$ \\
\hline \multicolumn{3}{|c|}{ Importance of Changing the Undergarments $(n=85)$} \\
\hline To maintain intimate hygiene & 46 & $54.1 \%$ \\
\hline $\begin{array}{l}\text { To prevent infection due to } \\
\text { sweating }\end{array}$ & 16 & $18.8 \%$ \\
\hline Do not know & 23 & $27.1 \%$ \\
\hline \multicolumn{3}{|c|}{ Undergarments Washed Daily ( $n=85$ ) } \\
\hline Yes & 82 & $96.5 \%$ \\
\hline No & 3 & $3.5 \%$ \\
\hline
\end{tabular}

\section{Knowledge and Practice of Bathing and Genital Hygiene}

It was found from the study that majority of the interviewed antenatal mothers (72.4\%) bathed once in a day while $71.8 \%$ and $88.2 \%$ used shampoo $2-3$ times a week to clean their hair and soap every time while bathing, respectively. $52.9 \%$ believed bathing is important to keep away germs. Ma-jority (95.3\%) changed their clothes after bathing. Most of them (44.7\%) cleaned their genital area once daily while $2.4 \%$ are not in a habit of cleaning their genital area. Majority (76.5\%) used soap and water to clean their genital area. Only 1 antenatal mother answered that she cleaned her genital area with mud. $83.5 \%$ of the antenatal mothers washed their nipples with soap and water regularly among which $70.4 \%$ were of the opinion that this is important to protect the newborn from any infection during the lactation period by keeping their nipples clean. $50 \%$ of the antenatal mothers were not in a habit of using undergarments during pregnancy while the remaining $50 \%$ used undergarments among which majority (96.5\%) cleaned their undergarments daily (Table 4).

Table 5.Distribution of the Interviewed Antenatal Mothers according to their Knowledge and Practice of Hand Washing $(\mathrm{N}=170)$

\begin{tabular}{|c|c|c|}
\hline & Number & Percentage \\
\hline \multicolumn{3}{|c|}{ Hands Washed Before Eating } \\
\hline Yes & 169 & $99.4 \%$ \\
\hline No & 1 & $0.6 \%$ \\
\hline Hands Washed after Defecation/ Using the Toilet \\
\hline Yes & 169 & $99.4 \%$ \\
\hline No & 1 & $0.6 \%$ \\
\hline Hands Washed Before Serving Food \\
\hline Yes & 165 & $97.1 \%$ \\
\hline No & 5 & $2.9 \%$ \\
\hline
\end{tabular}

Hands Washed every time after Returning Home from Outside

\begin{tabular}{|c|c|c|}
\hline Yes & 166 & $97.6 \%$ \\
\hline No & 4 & $2.4 \%$ \\
\hline
\end{tabular}

Hands Washed after Cleaning anyone Else's (Elderly, Sick, Children) Stool/ Urine

\begin{tabular}{|c|c|c|}
\hline Yes & 170 & $100 \%$ \\
\hline No & - & - \\
\hline
\end{tabular}

How Often Soap is Used While Wasing Hands

\begin{tabular}{|c|c|c|}
\hline Every time & 122 & $71.8 \%$ \\
\hline Occasionally & 45 & $26.5 \%$ \\
\hline Never & 3 & $1.7 \%$ \\
\hline Importance of Washing Hands with Soap
\end{tabular}

To keep the hands free from

\begin{tabular}{c|c|c}
$\begin{array}{l}\text { To keep the hands free from } \\
\text { germs and prevent diseases }\end{array}$ & 149 & $87.6 \%$ \\
\hline Do not think it is important & 21 & $12.4 \%$ \\
\hline
\end{tabular}

\begin{tabular}{l|l|l} 
Do not think it is important & 21 & $12.4 \%$
\end{tabular}

Know about the 6 Steps of Hand Washing

\begin{tabular}{|c|c|c|}
\hline Yes & 41 & $24.1 \%$ \\
\hline No & 129 & $75.9 \%$ \\
\hline
\end{tabular}

If Yes, Can Demonstrate the 6 Steps $(n=41)$

\begin{tabular}{|c|c|c|}
\hline Yes & 25 & $61 \%$ \\
\hline No & 16 & $39 \%$ \\
\hline
\end{tabular}


Table 6.Distribution of the Interviewed Antenatal Mothers according to their knowledge and Practice of Cutting Nails ( $\mathbf{N}=\mathbf{I 7 0})$

\begin{tabular}{|c|c|c|}
\hline & Number & Percentage \\
\hline \multicolumn{3}{|l|}{ How often Nails are Cut } \\
\hline Weekly & 110 & $64.7 \%$ \\
\hline Monthly & 20 & $11.8 \%$ \\
\hline Every alternate month & 3 & $1.7 \%$ \\
\hline Every time the nails grow big & 37 & $21.8 \%$ \\
\hline \multicolumn{3}{|c|}{ Importance of Cutting the Nails Regularly } \\
\hline $\begin{array}{c}\text { To keeps away germs as germs } \\
\text { stuck in the nails can cause } \\
\text { diseases like diarrhoea etc }\end{array}$ & 150 & $88.2 \%$ \\
\hline Long nails look untidy & 18 & $10.6 \%$ \\
\hline Do not know & 2 & $1.2 \%$ \\
\hline \multicolumn{3}{|c|}{ Have a Habit of Biting Nails } \\
\hline Yes & 33 & $19.4 \%$ \\
\hline No & 137 & $80.6 \%$ \\
\hline
\end{tabular}

\section{Knowledge and Practice of Hand Washing}

The study revealed that majority of the interviewed antenatal mothers washed their hands before eating $(99.4 \%)$, after using the toilet $(99.4 \%)$, before serving food $(97.1 \%)$ and every time after returning home from outside $(97.6 \%)$ while all of them washed their hands after cleaning anyone else's stool and urine. Most of them (71.8\%) used soap every time while washing hands while $26.5 \%$ used it occasionally and $1.7 \%$ did not use soap at all to wash their hands. $87.6 \%$ believed washing hands with soap is important to keep away germs and diseases. Majority (75.9\%) did not know about the 6 steps of hand washing (Table 5).

\section{Knowledge and Practice of Cutting Nails}

The date provided in the table shows that $64.7 \%$ of the interviewed antenatal mothers had a habit of cutting their nails weekly and majority ( $88.2 \%$ ) opined that cutting the nails at regular intervals helps to keep away germs and diseases. $19.4 \%$ had a habit of biting their nails (Table 6).

\section{Knowledge and Practice of Sanitation}

It was observed in the study that majority of the interviewed antenatal mothers (37.7\%) used domestic filter as their source of drinking water.

92.9\% of the interviewed antenatal mothers had a toilet in their house while $7.1 \%$ used community toilets. Majority (55.3\%) answered that their toilets are cleaned once a week. Most of them (44.7\%) opined that use of toilet is necessary to prevent access of animals and flies to the urine and faecal matter and $31.1 \%$ answered that it is necessary to prevent pollution of ground water and soil (Table 7).

Table 7.Distribution of the Interviewed Antenatal Mothers according to their Knowledge and Practice of Sanitation $(\mathbf{N}=$ I 70)

\begin{tabular}{|c|c|c|}
\hline & Number & Percentage \\
\hline \multicolumn{3}{|c|}{ Source of Drinking Water } \\
\hline Packaged water & 47 & $27.6 \%$ \\
\hline Domestic filter & 64 & $37.7 \%$ \\
\hline Tube well & 52 & $30.6 \%$ \\
\hline Dug well & 5 & $2.9 \%$ \\
\hline Pond water & 2 & $1.2 \%$ \\
\hline \multicolumn{3}{|c|}{ Have a Toilet in the Household } \\
\hline Yes & 158 & $92.9 \%$ \\
\hline No & 12 & $7.1 \%$ \\
\hline \multicolumn{3}{|c|}{ Use a Community Toilet } \\
\hline Yes & 12 & $7.1 \%$ \\
\hline No & 158 & $92.9 \%$ \\
\hline \multicolumn{3}{|c|}{ How Often the Toilet is Cleaned } \\
\hline Every day & 27 & $15.9 \%$ \\
\hline 2-3 times a week & 33 & $19.4 \%$ \\
\hline Once a week & 94 & $55.3 \%$ \\
\hline Once in 2 weeks & 13 & $7.7 \%$ \\
\hline Once a month & 3 & $1.7 \%$ \\
\hline \multicolumn{3}{|c|}{$\begin{array}{c}\text { Importance of Using a Toilet for Urination and } \\
\text { Defecation }\end{array}$} \\
\hline $\begin{array}{l}\text { Prevent pollution of ground } \\
\text { water and soil }\end{array}$ & 53 & $31.1 \%$ \\
\hline $\begin{array}{c}\text { Prevent nuisance of odour and } \\
\text { unsightly appearance }\end{array}$ & 37 & $21.8 \%$ \\
\hline $\begin{array}{l}\text { Prevent access of animals and } \\
\text { flies }\end{array}$ & 76 & $44.7 \%$ \\
\hline Provide privacy and security & 4 & $2.4 \%$ \\
\hline
\end{tabular}

\section{Discussion}

Regarding and sociodemographic profile, majority of the interviewed antenatal mothers (98.2\%) in the current study were housewives and $41.8 \%$ was in the age group $25-30$ years. $97.1 \%$ of them was literate with majority (46.5\%) having completed their secondary education. Among the hus-bands, $1.9 \%$ was illiterate. According to modified BG Prasad socioeconomic classification (2019), ${ }^{10}$ majority of the study population (43.5\%) belonged to upper middle class.58.8\% had had more than 4 antenatal checkups at 
the time of the interview. In the study conducted by Ray et al. (2012) in a rural community of West Bengal, 95.2\% of the antenatal mothers were housewives and majority of them $(68.7 \%)$ was between 19 and 25 years of age. $18.1 \%$ of the antenatal mothers were illiterate while among the husbands, $10.8 \%$ were illiterate. According to BG Prasad socioeconomic classifica-tion, $49.5 \%$ of them belonged to the lower middle class. ${ }^{11}$ In the same study, majority of them $(60.4 \%)$ were multigravida ${ }^{11}$ in contrast to the present study where majority $(63.5 \%)$ of the antenatal mothers were primigravida. Patrick Martial Nkamedjie Pete et al. (2013) observed in their study in Cameroon that majority of the participating mothers (46.2\%) was between $15-25$ years of age $33.8 \%$ were housewives and $2.4 \%$ had had no education at all. ${ }^{12}$

Regarding breastfeeding knowledge it has been observed in the present study, that $73.5 \%$ of the antenatal mothers intended to feed colostrum to the newborn among which $66.4 \%$ cited growth and development of child as well as development of immunity in the child as the reasons for feeding colostrum. $8.8 \%$ of the antenatal mothers opined that colostrum should be discarded while $17.7 \%$ did not know what colostrum is. The knowledge about colostrum was higher among multigravida women. $98.2 \%$ opined that breastmilk should be fed to the child first after birth while the others were of the opinion that honey should be fed first. $94.7 \%$ of the study population answered that exclusive breastfeeding is the best source of nutrients for their children in the first 6 months of life. 54.7\% believed that water can be given to the child during exclusive breastfeeding. 43.5\% answered that their children should be breastfed every 1-2 hours. 91.8\% knew about the correct age of starting complementary feeding. $44.1 \%$ of the antenatal mothers were of the opinion that breastfeeding should be completely stopped 2 years after the birth of the child.77.1\% of the antenatal mothers did not believe that breastmilk supplements and breastmilk have the same nutritional value while $80 \%$ believed that breastmilk is digested faster than breastmilk supplement. Ray et al. (2012) observed in a rural community of West Bengal that $57.8 \%$ of the antenatal mothers considered breastmilk as the ideal food that is to be provided to the child after birth while the remaining opined that honey, water etc. should be fed to the child first after birth.63.9\% of them knew that their child should be exclusively breastfed during the first 6 months of life while $71.1 \%$ of the study partici-pants knew about the correct age of beginning complementary feeding and $96.4 \%$ believed that breastfeeding was essential for the growth and development of the child and also for the prevention of infections. It was observed in the same study that $71.1 \%$ of the antenatal mothers was aware that breastfeeding should be continued for more than
2 years along with other food while $79.5 \%$ knew that it can be continued during any illness. ${ }^{11}$ De et al. reported that $39.6 \%$ of the antenatal mothers in their study(2015) in Kolkata believed colostrum to be beneficial for the newborn while $9.1 \%$ considered it to be harmful and $51 \%$ did not know what colostrum is. $81.3 \%$ opined that breastmilk should be fed to the newborn first after birth. $70.8 \%$ of participants of the same study was aware about exclusive breast-feeding and $69.1 \%$ knew that it should be continued for the first 6 months. $73.5 \%$ opined that their children should be demand fed. They also observed that $54.2 \%$ of the antenatal mothers believed that breastfeeding can be continued during any illness. ${ }^{13}$ According to another study conducted between January 2015 and December 2016 in Nalanda, Bihar by Tiwari et al, only $18 \%$ of the antenatal mothers of the study population knew about exclusive breastfeeding. However, knowledge about breastmilk supplements was much higher (76\%). Majority of the antenatal mothers did not know what colostrum is. It was observed in the same study that the role played by medical fraternity in imparting knowledge about the nutrition of the infant was minimal (18\%). ${ }^{14}$

Batool Karimi et al observed that among antenatal mothers in Semnan, Iran, $77.5 \%$ believed that colostrum should be fed to the newborn. $78.5 \%$ believed that breast milk led to better development of their children in comparison to formula feeding and $94 \%$ considered breastmilk to be more nutritious than the formulated milk products. ${ }^{15}$ According to a cross-sectional analytical study (2014) conducted among primiparous and multiparous mothers in Wajir District hospital, Wajir County, Kenya by Mahat Jimale Mohamed et al., $98.6 \%$ and $86.8 \%$ of the primiparous and multiparous mothers respectively, in the study population was aware that breastmilk should be the baby's first feed after birth. $87.6 \%$ and $84.7 \%$ of the primiparous and multiparous mothers, respectively knew that colostrum should be fed to the child. $78.1 \%$ and $78.5 \%$ of the primiparous and multiparous mothers, respectively, knew that their child should be exclusively breastfed during the first 6 months of life. $75 \%$ and $67.4 \%$ of the primiparous and multiparous mothers, respectively knew about the correct age of beginning complementary feeding. ${ }^{16}$ In a study conducted among antenatal mothers between December 2015 and February 2016 in Edward Francis Small Teaching Hospital, Banjul, The Gambia, Senghore et al found that the proportion of women with sufficient knowledge on exclusive breastfeeding and intended to practise exclusive breastfeeding were $60.2 \%$ and $38.6 \%$ respectively, while only $34.4 \%$ received counselling about breastfeeding. ${ }^{17}$ In a study in Shanghai, China it was observed that $84.3 \%$ of the antenatal mothers believed that colostrum should be fed to the newborn and $99 \%$ were aware about the benefits of breastfeeding. ${ }^{18}$ In a 
study in Malaysia,74.8\% of the participating antenatal mothers were knowledgeable about breastfeeding with total score of more than $70 \%$. They acknowledged that colostrum and breastmilk as the best food for infants. They knew that colostrum helps in the growth of the child and protection against various infections and diseases as well as maternal recovery after birth. ${ }^{19}$

The practice of hygiene among the antenatal mothers is crucial for both the mother and the child. In the present study, it was found that $72.4 \%$ of the antenatal mothers bathed once in a day while $71.8 \%$ and $88.2 \%$ used shampoo 2-3 times a week to clean their hair and soap every time while bathing, respectively. Out of them $52.9 \%$ believed bathing is important to keep away germs and $95.3 \%$ changed their clothes after bathing.

With regards to oral hygiene, it was observed in the present study, that $75.9 \%$ of the interviewed antenatal mothers cleaned their teeth twice daily, i.e, before breakfast and before going to bed at night while $19.4 \%, 0.6 \%$ and $2.4 \%$ cleaned their teeth only after breakfast, before going to bed at night, after every major meal, respectively. Ravleen Nagi et al. observed in a study that $99.8 \%$ of the antenatal mothers in Chattisgarh brushed at least twice daily while $50.2 \%$ brushed daily before breakfast and after dinner. ${ }^{20}$ Shimaa Abdelrahim Khalaf et al (2017) observed in Assuit, Egypt that $51.6 \%$ and $21.4 \%$ of the antenatal mothers brushed only in the morning and after each meal, respectively while only $9.4 \%$ of them brushed daily before breakfast and after dinner. $41.1 \%$ of the participants knew that teeth are cleaned to prevent dental caries while only $8.8 \%$ believed that gum dis-eases can be avoided by regular brushing of teeth. $47.4 \%$ of them did not about the importance of regular brushing of teeth. They observed that $85.9 \%$ used a toothbrush to clean their teeth. ${ }^{8}$ In the present study, it was observed that $97.6 \%$ of the interviewed antenatal mothers used a toothbrush and $41.8 \%$ answered that teeth should be daily cleaned to prevent food from getting stuck in the teeth; $15.3 \%$ believed that gum diseases can be avoided by regular brushing of teeth and $40 \%$ brushed their teeth daily to avoid bad breath while $2.9 \%$ did not about the importance of regular brushing of teeth.

With regards to genital hygiene, Patrick Martial Nkamedjie Pete et al. (2013) reported that $66.3 \%$ of the antenatal mothers cleaned the vagina and vulva simultaneously. Majority of them (63.8\%) used non-irritant agent like water for cleaning the genital area. Almost one participant on four used antiseptic solutions for genital cleaning (vulva area and vagina). Antiseptic solutions along with water were used only by $34.5 \%$ of the participants while in $65 \%$ of the cases it was used only for cleaning the vagina. ${ }^{12}$ In the present study, it was observed that $44.7 \%$ cleaned their genital area once daily and $76.5 \%$ cleaned it with soap and water.

Bijaya K. Padhi et al. observed in a cohort study in coastal and inland tribal settings of Odisha, India that $58.2 \%$ of the antenatal mothers did not have any access to latrines and defecated in open fields while $45.8 \%$ of them living in households with access to latrines used them regularly and $32 \%$ rarely used latrines. Water source was present in about $60 \%$ of the latrines and faecal contamination was seen on the floor in $21.5 \%$ of the latrines. $58 \%$ of the antenatal mothers did not wash their hands with soap or detergent after defecation and $14.7 \%$ of the study participants used pipe water for bathing. ${ }^{21}$

In the present study, it was observed that majority of the antenatal mothers (37.7\%) used domestic filter as their source of drinking water.

Majority of them (92.9\%) had a toilet in their house while $7.1 \%$ used community toilets. Most of them (55.3\%) answered that their toilets are cleaned once a week and $44.7 \%$ opined that use of toilet is necessary to prevent access of animals and flies to the urine and faecal matterand $31.1 \%$ answered that it is necessary to prevent pollution of ground water and soil.

In the present study, majority of the antenatal mothers washed their hands before eating (99.4\%), after using the toilet (99.4\%), before serving food (97.1\%) and every time after returning home from outside (97.6\%)while all of them washed their hands after cleaning anyone else's stool and urine. Most of them (71.8\%) used soap every time while washing hands while $1.7 \%$ did not use soap at all to wash their hands. Out of them, $87.6 \%$ believed washing hands with soap is important to keep away germs and diseases and $75.9 \%$ did not know about the 6 steps of hand washing. Most of the antenatal mothers (64.7\%) had a habit of cutting their nails weekly and $88.2 \%$ opined that cutting the nails at regular intervals helps to keep away germs and diseases. Out of them, $19.4 \%$ had a habit of biting their nails.

\section{Conclusion}

Majority of the antenatal mothers had completed only their secondary education. It was observed that knowledge about colostrum was higher in the multigravida women.73.5\% of the interviewed antenatal mothers intended to feed colostrum to the newborn and majority had adequate knowledge about the importance of feeding colostrum as well as about the correct duration of exclusive breastfeeding and the correct age of initiating complementary feeding. However, most of them did not know what exclusive breastfeeding is in the true sense. Knowledge with respect to the time when breastfeeding should be completely stopped was found 
to be lacking among most of the antenatal mothers. Majority did not know that certain drugs when taken by them during the lactation period can affect their children through breastmilk. So healthcare staffs should emphasise the significance of exclusive breastfeeding as well as impart knowledge regarding the initiation, intervals and the age of stoppage of breastfeeding to the pregnant women in a language that they understand. This will help to lower the incidences of diarrhoea and malnutrition in the newborns and will reduce neonatal and post neonatal mortality rates. Knowledge as well as practices of hygiene of the antenatal mothers were found to be satisfactory. However, $50 \%$ of them were not in a habit of using undergarments which is a bad habit as it makes them susceptible to a variety of genital infections. The use of community toilets is still in vogue among $7.1 \%$ of them. Healthcare programmes should be organised promoting awareness and good hygiene practices among pregnant women.Education and awareness can promote the practice of hygiene among the antenatal mothers which is crucial for both the mother and the child.They can utilise this knowledge of personal hygiene in the postnatal period and can maintain the hygiene of the newborn as well. Practice of proper hygiene can reduce the incidences of diarrhoeal diseases, perineal sepsis, PID (pelvic Inflammatory Diseases), skin diseases and other infective conditions in the antenatal and postnatal mothers thereby reducing maternal and infant morbidity and mortality.

\section{Aknowledgement}

We would like to thank ICMR for giving us the opportunity to conduct this study and approving this as a part of their Short Term Studentship Program 2019.We would like to express our gratitude to Dr. Debjani Bhadra, HOD, Department of Obstetrics and Gynaecology, KPC Medical College and Hospital, Jadavpur, Kolkata, for her cooperation and valuable suggestions in the research. We would also like to thank the Department of Community Medicine, KPC Medical College and Hospital, Jadavpur, Kolkata, for providing the resources required for the development and conduction of the study.

\section{Conflicts of Interest: None}

\section{References}

1. World Health Organisation(WHO).Nutrition. Available from https://www.who.int/nutrition/topics/exclusive_ breastfeeding/en/ (Last accessed on 2019 Aug 18).

2. Park K. Preventive Medicine in Obstetrics, Paediatrics and Geriatrics. Park's Textbook of Preven-tive and Social Medicine. 25th ed., M/s Banarasidas Bhanot Publishers, 2019, 585, 590.

3. Kliegman, Stanton, St. Geme, Schor, Behrman. Nutrition. Nelson Textbook of Pediatrics. $19^{\text {th }}$ ed.,
Elsevier, 160-161.

4. Faridi MMA. Health Care System in the Protection, Promotion and Support of Breastfeeding. Solution Exchange for $\mathrm{MCH}$ Community Newsletter, Breastfeeding Month Special. 2008; 7-8.

5. Edmonds Keith D. Puerperium and lactation. Dewhurst' s Textbook of Obstetrics \& Gynaecology. 7th ed., Blackwell Publishing. 2007; 75.

6. Salhan Sudha. Breastfeeding. Textbook of Obstetrics. 1st ed., Jaypee Brothers Medical Publish-ers (P) LTD. 2007; 613.

7. Nun DR, Adesuyi EO, Olawoore SA. Knowledge Attitude and Prac-tices of Pregnant Women Attending Comprehensive Health Centre, Isolo, Ondo State towards Hygienic Practice. International Journal of Tropical Disease \& Health 2018; 30(2): 1-10.

8. Khalaf SA, Osman SR, Abbas AM, Abdul-Aziz MT Ismail. Knowledge, attitude and practice of oral healthcare among pregnant women in Assiut, Egypt. International Journal of Community Medicine and Public Health 2018; 5(3): 890-900.

9. Imade PE, Izekor PE, Eghafona NO, Enabulele OI. Endurance Ophori. Asymptomatic bacteriuria among pregnant women. North American Journal of Medical Sciences 2010; 2(6): 263-266.

10. Pandey V, Aggarwal P, Kakkar R. Modified BG Prasad Socio-economic Classification, Update - 2019. Indian J Community Health 2019; 31(1): 150-152.

11. Deepanjan R, Rahaman MDA, Aparajita D. Breastfeeding Knowledge among Antenatal Mothers: A Cross-Sectional Study in a Rural Area of West Bengal. IOSR Journal of Dental and Medical Sciences 2015; 14(5): 2015: 93-97.

12. Pete PMN, Biguioh RM, Bita Izacar AG, Adogaye SBB, Nguemo C. Genital hygiene behaviors and practices: A cross-sectional descriptive study among antenatal care attendees. J Public Health Afr 2019; 10(1): 746.

13. De Maumita, Pranita T, Shubhadeep P, Halder Anima. Awareness of Breast Feeding Among Mothers Attending Antenatal OPD of NRS Medical College. IOSR Journal of Dental and Medical Sciences 2016; 15(2): 3-8.

14. Kamlesh T, Neha S, Ishmat K. A study on knowledge of breast feeding and effect of antenatal counselling on exclusive breast feeding in primigravida mothers. International Journal of Reproduction, Contraception, Obstetrics and Gynecology 2018; 7(8): 3311-3315.

15. Karimi B, Zarei Sani M, Ghorbani R, Danai N. The Pregnant Mothers' Knowledge About Breastfeeding in Semnan, Iran. Middle East J Rehabil Health Stud 2014; 1(1): e20833. DOI: 10.17795/mejrh-20833 (Last accessed on 2019 Aug 25).

16. Mahat MJ, Sophie O, Victor OO. Comparison of 
knowledge, attitudes and practices on exclusive breastfeeding between primiparous and multiparous mothers attending Wajir District hospital, Wajir County, Kenya: a cross-sectional analytical study. International Breastfeeding Journal 2018.

17. Thomas S, Tobiloba OA, Omar C, Williams H. Clara Daisy.Predictors of exclusive breastfeeding knowledge and intention to or practice of exclusive breastfeeding among antenatal and postnatal women receiving routine care: a cross-sectional study. International Breastfeeding Journal 2018.

18. Hong Jiang, Mu Li, Dongling Yang et al. Awareness, Intention and Needs regarding Breast-feeding :Findings from first time mothers in Sanghai, China. Breastfeed Med 2012.

19. Tan $\mathrm{AE}$, Choong WK, Leong PY, Ng WM, Leong S. Knowledge, Attitudes and Sources of In-formation on Breastfeeding among Pregnant Mothers. Med Health 2008; 3(1): 30-37.

20. Ravleen N, Shashikant S, Rakesh N. Oral health, nutritional knowledge, and practices among pregnant women and their awareness relating to adverse pregnancy outcomes. Journal of Indian Academy of Oral Medicine \& Radiology 2016; 28(4): 396-402.

21. Bijaya PK, Kelly BK, Ambarish D, Oliver C, Mathew FC, Radhanatha S, Das SB, Pinaki P. Risk of adverse pregnancy outcomes among women practicing poor sanitation in rural India: a population-based prospective cohort study. PLos Medicine 2015; 12(7). 